\title{
Magnesium Depletion in Patients Treated with Therapeutic Hypothermia After Cardiac Arrest
}

\author{
Maryann Mazer-Amirshahi, ${ }^{1}$ Sarah M. Perman, ${ }^{2}$ Anne V. Grossestreuer, ${ }^{3}$ \\ Robert W. Neumar, ${ }^{4}$ and David F. Gaieski ${ }^{5}$
}

Magnesium $\left(\mathrm{Mg}^{2+}\right)$ depletion can have detrimental effects in postcardiac arrest patients through multiple potential mechanisms. Therapeutic hypothermia $(\mathrm{TH})$ produces a $\mathrm{Mg}^{2+}$ diuresis, but the effects of postcardiac arrest $\mathrm{TH}$ on serum $\mathrm{Mg}^{2+}$ levels in patients with postcardiac arrest syndrome (PCAS) are yet to be systematically quantified. We conducted a retrospective chart review of 119 consecutive comatose PCAS patients treated with TH between 2005 and 2010 and compared them to 33 matched historic controls (HCs) seen at the same institution between 2002 and 2005 who were not treated with TH. We abstracted data from the first 96 hours postarrest, including date, time, and value of serum $\mathrm{Mg}^{2+}$ levels and date, time, and amount of $\mathrm{Mg}^{2+}$ repletion, along with outcomes at discharge. The median $\mathrm{Mg}^{2+}$ level of $\mathrm{TH}$ patients was $2.0 \mathrm{mg} / \mathrm{dL}$ [interquartile range (IQR), $1.9-2.2 \mathrm{mg} / \mathrm{dL}](0.82 \mathrm{mmol} / \mathrm{L}$ [IQR, 0.78-0.90 mmol/L]) versus $2.2 \mathrm{mg} / \mathrm{dL}$ [IQR, $1.9-$ $2.4 \mathrm{mg} / \mathrm{dL}]\left(0.90 \mathrm{mmol} / \mathrm{L}\right.$ [IQR, 0.82-0.99 mmol/L]) $(p=0.2)$ in HCs. In addition, $42.9 \%(520 / 1214) \mathrm{of}^{2+}$ levels in TH patients versus 31.9\% (43/135) $(p=0.014)$ in HC patients were below $2.0 \mathrm{mg} / \mathrm{dL}$ [0.82 $\mathrm{mmol} / \mathrm{L}]$. The average number of times the $\mathrm{Mg}^{2+}$ level was checked in TH patients was 10.2 (range 1-18) versus 4.1 (range 1-10) in HCs. The TH patients were more likely to receive supplemental $\mathrm{Mg}^{2+}$ than $\mathrm{HCs}(81.5 \%$ [97/ $119]$ vs. $27.3 \%$ [9/33] $[p<0.01])$. The mean supplemental $\mathrm{Mg}^{2+}$ dose was $1.9 \mathrm{~g}$ for $\mathrm{TH}$ patients versus $0.5 \mathrm{~g}$ for HC patients. Mortality in patients treated with TH was $53.1 \%(60 / 113)$ versus $78.6 \%(22 / 28)(p=0.014)$ in HCs. Low serum $\mathrm{Mg}^{2+}$ levels with subsequent $\mathrm{Mg}^{2+}$ supplementation were more common in comatose patients with PCAS treated with TH compared to normothermic HC patients. The effect of untreated hypomagnesemia on postcardiac arrest outcomes remains to be determined.

\section{Introduction}

$\mathbf{M}$ AGNESIUM $\left(\mathrm{MG}^{2+}\right)$ IS A DivALENT CATION that has a multitude of physiologic effects. Its actions at the cellular level are primarily due to the effects of $\mathrm{Mg}^{2+}$ on calcium channels, hormone receptor binding sites, and through adenylate cyclase using second messenger systems (Altura, 1994; Fawcett et al., 1999). Magnesium is a cofactor in more than 300 enzymatic reactions throughout the body (Fawcett et al., 1999). Magnesium also has well-established effects on the myocardium and is critical in maintaining normal cardiac conduction (Iseri, 1990). In the brain, $\mathrm{Mg}^{2+}$ is a natural antagonist at the $\mathrm{N}$-methyl-D-aspartate (NMDA) receptor channel, and therefore, a potential modulator of neuronal irritability and excitotoxicity (Kuner and Schoepfer, 1996). Low serum $\mathrm{Mg}^{2+}$ levels have been associated with cardiac dysrhythmias (Fawcett et al., 1999), increases in proinflammatory cytokines (Weglicki et al., 1992), free radical injury, shivering in brain-injured patients (Badjatia et al., 2008; Polderman, 2009), and ultimately, cellular death (HACA, 2002).

Therapeutic hypothermia $(\mathrm{TH})$ has been demonstrated to improve neurologic outcomes in comatose patients with postcardiac arrest syndrome (PCAS) and has become a standard postresuscitation care in many institutions (HACA, 2002; Young, 2009; Hollenberg et al., 2013). In addition, it has been postulated that $\mathrm{Mg}^{2+}$ may have neuroprotective effects during the postcardiac arrest period and low serum

\footnotetext{
${ }^{1}$ Department of Emergency Medicine, MedStar Washington Hospital Center, Washington, District of Columbia.

${ }^{2}$ Department of Emergency Medicine, School of Medicine, University of Colorado, Aurora, Colorado.

${ }^{3}$ Department of Emergency Medicine, Center for Resuscitation Science, Philadelphia, Pennsylvania.

${ }^{4}$ Department of Emergency Medicine, School of Medicine, University of Michigan, Ann Arbor, Michigan.

${ }^{5}$ Department of Emergency Medicine, Center for Resuscitation Science, School of Medicine, University of Pennsylvania, Philadelphia, Pennsylvania.

Poster presentation at 2nd International Therapeutic Hypothermia Conference, Lund, Sweden, September 2009.
} 
$\mathrm{Mg}^{2+}$ levels may exacerbate neuronal injury, although this has not been studied in a controlled randomized manner (Reis et al., 2008). Despite the clear benefits of TH on neurologic outcomes, significant adverse effects have been associated with the use of TH. Electrolyte abnormalities, including hypokalemia, hypophosphatemia, and hypomagnesemia, have been noted in $\sim 20 \%$ of patients undergoing TH (Nielsen et al., 2009).

Although hypomagnesemia has not been definitively linked with adverse outcomes in the setting of postcardiac arrest TH, data are currently limited (Polderman, 2004; Nielsen et al., 2011; Tømte et al., 2011). At the same time, hypomagnesemia has been associated with adverse effects and increased mortality in medical patients with critical illness (Rubeiz et al., 1993; Soliman et al., 2003; Tømte et al., 2011). The effect of postcardiac arrest $\mathrm{TH}$ on $\mathrm{Mg}^{2+}$ levels has not been specifically investigated. The objective of this study was to determine if $\mathrm{TH}$ after cardiac arrest had a significant effect on serum $\mathrm{Mg}^{2+}$ levels and whether clinicians responded to low $\mathrm{Mg}^{2+}$ levels in TH patients by checking levels or repleting $\mathrm{Mg}^{2+}$ more frequently.

\section{Materials and Methods}

\section{Study design}

This study is a retrospective chart review of comatose patients with PCAS treated with TH between 2005 and 2010 compared to a cohort of comatose historical controls (HCs) who had a cardiac arrest between 2000 and 2005 and received standard postarrest care without $\mathrm{TH}$.

\section{Study setting and population}

The study was approved by the Institutional Review Board at the Hospital of the University of Pennsylvania and conducted at an urban teaching hospital with $\sim 58,000$ emergency department visits and 100 cardiac arrests annually during the time the study was conducted. Patients were included if they were $\geq 18$ years of age, suffered a cardiac arrest, and had return of spontaneous circulation (ROSC), but were subsequently comatose and treated with TH. Coma was defined as a Glasgow Coma Scale (GCS) $<6$ (specifically not following commands). HC patients would have been eligible for $\mathrm{TH}$ had the protocol existed at the time of their arrest but instead were treated with standard postresuscitation care, as TH was not the standard of care at that time.

\section{TH protocol}

TH was induced with chilled saline and continued with a surface cooling system with a target temperature of $33^{\circ} \mathrm{C}$. Ice packs were utilized if there was difficulty achieving or maintaining the target temperature with initial measures. TH was then maintained for 24 hours. Active rewarming was performed over at least 8 hours by increasing the temperature set point by $0.25-0.33^{\circ} \mathrm{C} /$ hour. In addition, patients received early hemodynamic optimization and standard intensive care unit measures. Institutional protocol recommends checking $\mathrm{Mg}^{2+}$ levels every 6 hours during all phases of TH. As part of the $\mathrm{TH}$ protocol, there is a computerized order set that prompts the clinician to order $2 \mathrm{~g} \mathrm{Mg}^{2+}$ IV if the serum $\mathrm{Mg}^{2+}$ level is $<1.8 \mathrm{~g} / \mathrm{dL}$.

\section{Data collection}

Data were obtained for both the $\mathrm{TH}$ and $\mathrm{HC}$ groups during the first 96 hours postarrest or until the time of death, whichever occurred first. Each patient's medical record was reviewed and data were extracted and entered into a Microsoft Excel 2007 database (Microsoft Corp, Redmond, WA). Specific information collected included the date, time, and value of serum $\mathrm{Mg}^{2+}$ levels, reported in $\mathrm{mg} / \mathrm{dL}$ and $\mathrm{mmol} / \mathrm{L}$, using the following conversion formula: $\mathrm{Mg}^{2+}$ level $(\mathrm{mg} / \mathrm{dL}) \times$ $0.4114=\mathrm{Mg}^{2+}$ level $(\mathrm{mmol} / \mathrm{L})$. In addition, we collected the date, time, and amount of $\mathrm{Mg}^{2+}$ repletion. The primary outcomes were serum $\mathrm{Mg}^{2+}$ levels and the total amount of $\mathrm{Mg}^{2+}$ supplementation that occurred during the study period. Secondary outcomes included neurologic outcome at hospital discharge, reported as cerebral performance category (dichotomized into good and poor outcomes) and survival to hospital discharge.

\section{Statistical analysis}

All data were analyzed using standard statistical software (Stata v.12.1, College Station, TX). Continuous data were analyzed by means with ranges and standard deviations for parametric data and medians with ranges for nonparametric data. Comparisons were made using the Student's $t$-test and Mann-Whitney $U$ tests. P-values of $<0.05$ were considered statistically significant. Categorical data were compared using Fischer's exact test.

\section{Results}

\section{Baseline characteristics and outcomes}

One hundred nineteen consecutive comatose PCAS patients were treated with $\mathrm{TH}$ and compared to $33 \mathrm{HCs}$ (Table $1)$. The mean age of $\mathrm{TH}$ patients versus $\mathrm{HC}$ patients was $59.8 \pm 15.3$ versus $54.9 \pm 16.2$ years $(p=0.14)$. Fifty-seven percent of TH patients were male compared with $52 \%$ for HCs $(p=0.62)$. African-Americans comprised $46 \%$ of the TH group versus $64 \%$ in the HCs. Ventricular fibrillation (VF) or pulseless ventricular tachycardia (VT) was the initial rhythm in $36 \%$ of TH patients and $39 \%$ of HCs $(p=0.72)$ Mortality in patients treated with TH was $54 \%(62 / 116)$ versus $79 \%(22 / 28)$ in HCs $(p=0.02)$ (see Table 1 for complete demographics and outcomes).

\section{Magnesium levels}

During the first 96 hours postarrest, patients in the TH group had $\mathrm{Mg}^{2+}$ levels checked more frequently compared to HC patients. The average number of times the $\mathrm{Mg}^{2+}$ level checked in $\mathrm{TH}$ patients was $10.2 \pm 3.4$ versus $4.1 \pm 2.6$ times in $\mathrm{HCs}$ $(p<0.01)$. TH patients had lower median serum $\mathrm{Mg}^{2+}$ levels $(2.0 \mathrm{mg} / \mathrm{dL}$; interquartile range (IQR), $1.9-2.2 \mathrm{mg} / \mathrm{dL})$ ( $0.82 \mathrm{mmol} / \mathrm{L}$ [IQR, $0.78-0.90 \mathrm{mmol} / \mathrm{L}])$ than $\mathrm{HC}$ patients $(2.2 \mathrm{mg} / \mathrm{dL}, \mathrm{IQR}, 1.9-2.4 \mathrm{mg} / \mathrm{dL} ; p=0.2)(0.90 \mathrm{mmol} / \mathrm{L}[\mathrm{IQR}$, $0.82-0.99 \mathrm{mmol} / \mathrm{L}])$. A higher percentage of $\mathrm{Mg}^{2+}$ levels were below $2.0 \mathrm{mg} / \mathrm{dL}(0.2 \mathrm{mmol} / \mathrm{L})$ in $\mathrm{TH}$ patients than in $\mathrm{HC}$ patients $(42.9 \%$ [520/1214] vs. $31.9 \%$ [43/135]; $p=0.014)$. Patients treated with TH were more likely to be given supplemental $\mathrm{Mg}^{2+}$ than $\mathrm{HC}$ patients (81.5\% [97/119] vs. $27.3 \%$ [9/33]; $p<0.01)$. The mean $\mathrm{Mg}^{2+}$ dose administered to $\mathrm{TH}$ patients was $1.9 \pm 1.3$ versus $0.5 \pm 0.9 \mathrm{~g}(p<0.01)$ for $\mathrm{HC}$ 
Table 1. Comparison of Demographics and Outcomes Between Therapeutic Hypothermia PATIENTS AND Historic CONTROLS

\begin{tabular}{|c|c|c|c|}
\hline Parameter & $\begin{array}{l}\text { Therapeutic hypothermia } \\
\qquad(\mathrm{n}=119)\end{array}$ & $\begin{array}{l}\text { Historic controls } \\
\quad(\mathrm{n}=33)\end{array}$ & $\mathrm{p}$-Value \\
\hline Mean age (years) (SD) & $59.8 \pm 15.3$ & $54.9 \pm 16.2$ & NS \\
\hline Male sex $(\%)$ & $68 / 119(57 \%)$ & $14 / 27(52 \%)$ & NS \\
\hline African-American (\%) & $55 / 119(46 \%)$ & $17 / 28(61 \%)$ & NS \\
\hline Caucasian $(\%)$ & $55 / 119(46 \%)$ & $9 / 28(32 \%)$ & NS \\
\hline Initial rhythm, $\mathrm{VF}$, or pVT $(\%)$ & $43 / 119(36 \%)$ & $11 / 28(39 \%)$ & NS \\
\hline Initial GCS recorded after ROSC (range 3-15) & 4 & 5 & NS \\
\hline Mortality $(\%)$ & $62 / 116(54 \%)$ & $22 / 28(79 \%)$ & 0.02 \\
\hline $\begin{array}{l}\text { Good neurological outcome at hospital discharge } \\
\text { (CPC } 1 \text { or } 2 \text { ) }\end{array}$ & $42 / 53(79 \%)$ & $6 / 6(100 \%)$ & NS \\
\hline
\end{tabular}

CPC, cerebral performance category; GCS, Glasgow Coma Scale; NS, nonsignificant; pVT, pulseless ventricular tachycardia; ROSC, return of spontaneous circulation; SD, standard deviation; VF, ventricular fibrillation.

patients. Postarrest $\mathrm{TH}$ patients given $\mathrm{Mg}^{2+}$ supplementation received an average total $\mathrm{Mg}^{2+}$ dose of $3.8 \pm 3.2$ versus $0.7 \pm 1.5 \mathrm{~g}(p<0.01)$ for HC patients (Table 2; Fig. 1).

\section{Adverse effects in $\mathrm{TH}$ patients}

Thirty-eight percent (45/119) of patients had major adverse effects of TH therapy (defined as postarrest fever, skin breakdown, shivering, and dysrhythmias). The most common side effect noted was postarrest fever $(n=26)$, followed by skin breakdown $(n=12)$, shivering $(n=8)$, and dysrhythmias $(n=5)$. Patients with adverse effects had significantly lower mean $\mathrm{Mg}^{2+}$ levels than those without adverse effects $(1.98 \pm$ $0.18 \mathrm{mg} / \mathrm{dL}[0.81 \mathrm{mmol} / \mathrm{L}]$ vs. $2.07 \pm 0.28 \mathrm{mg} / \mathrm{dL} \quad[0.85$ $\mathrm{mmol} / \mathrm{L}] ; p=0.015)$. They also had more $\mathrm{Mg}^{2+}$ repletion $(2.33 \pm 1.21$ vs. $1.27 \pm 1.23 \mathrm{~g} ; p<0.001)$.

\section{Discussion}

This preliminary investigation suggests that comatose PCAS patients undergoing treatment with $\mathrm{TH}$ are more likely to have lower serum $\mathrm{Mg}^{2+}$ levels and receive more $\mathrm{Mg}^{2+}$ repletion than patients who do not receive $\mathrm{TH}$. These findings could be the result of $\mathrm{TH}$-associated hypomagnesemia or that providers at our institution became more vigilant about monitoring serum $\mathrm{Mg}^{2+}$ levels and repleting $\mathrm{Mg}^{2+}$ compared to the pre-TH era, particularly with an electronic $\mathrm{TH}$ order protocol in place. Ultimately, it is likely that a combination of these factors is at play. Clinicians checked $\mathrm{Mg}^{2+}$ levels more frequently in a higher percentage of TH patients and responded to low or low normal levels by repleting $\mathrm{Mg}^{2+}$ more aggressively in this population. Despite this increased vigilance, mean serum $\mathrm{Mg}^{2+}$ levels were lower in $\mathrm{TH}$ patients than in $\mathrm{HC}$ patients.

Magnesium wasting is a well-described phenomenon during $\mathrm{TH}$ and results from increased fluid diuresis and temperaturesensitive changes in $\mathrm{Mg}^{2+}$ ion resorption channels in the ascending loop of Henle and the distal tubule of the kidney (Salem et al., 1995; Weisinger and Bellorin-Font, 1998), which ultimately promote $\mathrm{Mg}^{2+}$ excretion. It has also been demonstrated that induction of hypothermia causes the shift of electrolytes from the extracellular to the intracellular compartments (Longstreth et al., 2002). Interestingly, a study by Tømte et al. (2011) found a greater degree of intracellular shifting in patients who underwent induction of TH with corecooling measures compared to surface cooling; however, the underlying mechanism of this phenomenon is yet to be elucidated. It is unclear what percentage of changes in $\mathrm{Mg}^{2+}$ levels is due to intracellular shift and what percentage due to temperature-dependent $\mathrm{Mg}^{2+}$ wasting. In traumatic brain injury (TBI) patients with increased ICP treated with TH, Polderman et al. (2001) demonstrated statistically significantly increased urine excretion of $\mathrm{Mg}^{2+}$ during cooling, which reverted to baseline levels after rewarming $(3.7 \pm 1.7 \mathrm{mmol}$ in 6 hours before cooling; $9.5 \pm 4.7 \mathrm{mmol} / 6$ hours during cooling; $3.1 \pm 1.2 \mathrm{mmol}$ in 6 hours after cooling; $p<0.01)$. The authors reached very similar conclusions as we did: magnesium "depletion occurred (in the cooling group) despite the fact that moderate and, in some cases, substantial doses of (magnesium) repletion were given to many patients (Polderman et al., 2001)."

Table 2. Comparison of Magnesium Results Between Therapeutic Hypothermia Patients AND Historic CONTROLS

\begin{tabular}{|c|c|c|c|}
\hline Parameter & $\begin{array}{l}\text { Therapeutic hypothermia } \\
(\mathrm{n}=119)\end{array}$ & $\begin{array}{l}\text { Historic controls } \\
\quad(\mathrm{n}=33)\end{array}$ & p-Value \\
\hline Patients who had $\mathrm{Mg}^{2+}$ checked $(\%)$ & $119(100 \%)$ & $33(100 \%)$ & 1.00 \\
\hline $\begin{array}{l}\text { Mean } \mathrm{Mg}^{2+} \text { level, mg/dL (IQR) } \\
{[\mathrm{mmol} / \mathrm{L}(\mathrm{IQR})]}\end{array}$ & $2.0(1.9-2.2)[0.82(0.78-0.90)]$ & $2.2(1.9-2.4)[0.90(0.82-0.99)]$ & 0.2 \\
\hline Mean No. of serum $\mathrm{Mg}^{2+}$ checks (range) & $10.2(1-18)$ & $4.1(1-10)$ & $<0.01$ \\
\hline $\begin{array}{l}\text { No. of } \mathrm{Mg}^{2+} \text { values below } 2 \mathrm{mg} / \mathrm{dL} \\
{[0.82 \mathrm{mmol} / \mathrm{L}](\%)}\end{array}$ & $66(47.5 \%)$ & $8(21.6 \%)$ & 0.005 \\
\hline No. of patients given $\mathrm{Mg}^{2+}$ repletion (\%) & $97(81.5 \%)$ & $9(27.3 \%)$ & $<0.01$ \\
\hline
\end{tabular}

IQR, interquartile range. 


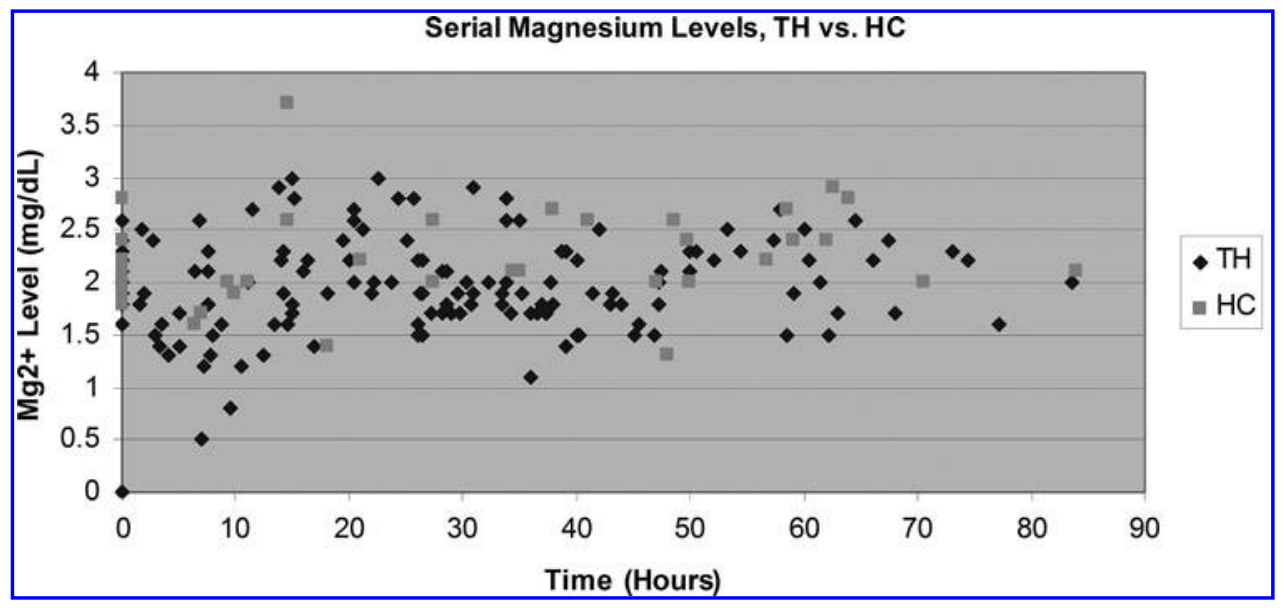

FIG. 1. Magnesium values over time for $\mathrm{TH}$ and $\mathrm{HC}$ patients. HC, historic controls; TH, therapeutic hypothermia.

PCAS is a dynamic critical illness that affects multiple organ systems, with particular impact on the brain and heart. It triggers a wide range of pathophysiologic processes, including amplified production of inflammatory markers, free radical generation, mitochondrial and endothelial dysfunction, and cellular apoptosis (HACA, 2002; Young, 2009; Hollenberg et al., 2013). Because $\mathrm{Mg}^{2+}$ plays a critical role in all of these processes, the effects of hypomagnesemia and the importance of subsequent $\mathrm{Mg}^{2+}$ repletion in PCAS patients may have significant clinical implications (Weglicki et al., 1992; Weisinger and Bellorin-Font, 1998; Fawcett et al., 1999; Iseri, 1990). Patients with PCAS are predisposed to cardiac dysrhythmias, such as VT and VF, as well as neuronal dysfunction, all of which may be exacerbated by hypomagnesemia (Soliman et al., 2003; Polderman, 2004; Polderman, 2009; Nielsen et al., 2011).

The extent to which hypomagnesemia affects clinical outcomes in patients undergoing $\mathrm{TH}$ postcardiac arrest remains unclear. We found significantly lower $\mathrm{Mg}^{2+}$ levels in patients with adverse effects of $\mathrm{TH}$ versus those without adverse effects of TH. A study by Nielsen et al. (2011) did not find an association between hypomagnesemia and increased mortality in PCAS patients treated with TH. In an attempt to further explore this question, Longstreth et al. conducted a randomized controlled trial of infusion of $\mathrm{Mg}^{2+}$, diazepam, or both, immediately after ROSC to comatose survivors of cardiac arrest. After controlling for potential confounders, there was no difference in outcomes between the treatment arms (Longstreth et al., 2002). The Duke Internal Medicine Housestaff performed a randomized trial of magnesium infusion during cardiac arrest for patients with in-hospital cardiac arrest at Duke Hospital. Seventy-six patients randomized to receive a bolus of $2 \mathrm{~g}$ of $\mathrm{Mg}^{2+}$ during arrest followed by $8 \mathrm{~g}$ of $\mathrm{Mg}^{2+}$ over the next 24 hours were compared to 80 patients who received placebo. The investigators found no differences between the groups in the percentages who achieved ROSC, survival to hospital discharge, or good neurological outcomes (Thel et al., 1997). However, these approaches of intra-arrest, immediate post-ROSC, or prophylactic infusion of $\mathrm{Mg}^{2+}$ are significantly different from the measurement and maintenance of normal $\mathrm{Mg}^{2+}$ levels over the 96-hour postarrest period. Ultimately, the true clinical impact of TH-induced hypomagnesemia as well as the optimal management strategy is yet to be determined.
Our results suggest that hypomagnesemia occurs in a significant percentage of PCAS patients undergoing TH and this finding may have relevance when designing and implementing the optimal management strategy and institutional TH protocols. This is particularly important because of the critically ill nature of the patients involved. Institutional TH protocols should be designed not only to prompt providers to frequently monitor $\mathrm{Mg}^{2+}$ levels but also to provide adequate $\mathrm{Mg}^{2+}$ repletion. Based on prior data, patients who undergo TH with core-cooling measures may be at higher risk for hypomagnesemia and may require more vigilant monitoring and intervention (Tømte et al., 2011). It is also important to keep in mind that hypomagnesemia may persist despite aggressive repletion. For example, as noted previously, Polderman et al. (2001) documented a similar $\mathrm{Mg}^{2+}$ diuresis in patients with TBI treated with $\mathrm{TH}$, where the urine output increased and serum $\mathrm{Mg}^{2+}$ levels decreased despite significant $\mathrm{Mg}^{2+}$ repletion. In a subsequent review of the mechanism of action, physiological effects, and complications associated with $\mathrm{TH}$, Polderman suggested that $\mathrm{Mg}^{2+}$ levels "should be kept in the high normal range during and after hypothermia treatment (Polderman, 2009). Extrapolation of these findings to patients treated with postcardiac arrest $\mathrm{TH}$ is difficult because a significant percentage of the TH-TBI patients were also treated with mannitol, a potent osmotic agent, which was not used in our patient population.

Our study raises important questions regarding $\mathrm{Mg}^{2+}$ monitoring and repletion in the postarrest state, which represents an opportunity for future research. Should $\mathrm{Mg}^{2+}$ levels be corrected only when they fall below the lower reference range of normal or should prophylactic supplementation be instituted? Should $\mathrm{Mg}^{2+}$ levels be aggressively maintained in a normal range to treat and prevent shivering and other side effects of cooling? Or should $\mathrm{Mg}^{2+}$ be infused until supratherapeutic levels are achieved to optimize organ protection? These questions remain unanswered. It is also unclear to what extent $\mathrm{TH}$-induced hypomagnesemia affects clinical outcomes. Finally, systematic studies should be performed to evaluate whether a synergistic neuroprotective effect of $\mathrm{Mg}^{2+}$ supplementation and TH exists. Because of the critically ill nature of PCAS patients undergoing TH and the lack of data regarding the outcomes associated with associated hypomagnesemia, we recommend that clinicians treating these patients should monitor serum $\mathrm{Mg}^{2+}$ levels on 
a frequent set schedule and aggressively replete $\mathrm{Mg}^{2+}$ to maintain levels in the midrange of normal. In addition, efforts should be made to educate physicians and other healthcare providers who manage $\mathrm{TH}$ patients regarding the potential for hypomagnesemia.

\section{Limitations}

Our study is limited by its small sample size and retrospective design. Furthermore, the number of patients in the $\mathrm{HC}$ group is approximately half of that in the hypothermia group. We speculate that this occurred for a number of reasons. (1) Inherent limitations in historic chart reviews, including insufficient documentation of neurologic status to determine coma postarrest; (2) changes in the Philadelphia Emergency Medical Services leading to increased numbers of arrests brought to our hospitals; and (3) referrals to our center as we established ourselves as a cardiac arrest center. In addition, $\mathrm{Mg}^{2+}$ levels were checked less frequently in historical control patients and there was no specific protocol for repletion in those patients. Provider knowledge of TH-induced hypomagnesemia was not evaluated. We did not explore the adverse events related to hypomagnesemia, and this study was not designed to assess a clinical benefit from maintaining a normal $\mathrm{Mg}^{2+}$ level when treating PCAS patients with TH.

\section{Conclusions}

Targeted temperature management is now considered the standard of care to optimize neurological recovery in comatose PCAS patients. Our results suggest that TH induces a significant $\mathrm{Mg}^{2+}$ diuresis and intracellular shifting, requiring frequent monitoring of serum $\mathrm{Mg}^{2+}$ levels and adequate $\mathrm{Mg}^{2+}$ repletion, with a goal of keeping serum levels within the normal range. Given its possible neuroprotective effect, standardized intervals for checking and repleting $\mathrm{Mg}^{2+}$ may improve the care of comatose PCAS patients undergoing treatment with TH. Additional studies should be performed to investigate the clinical effects of TH-induced hypomagnesemia and whether there is a relationship between $\mathrm{Mg}^{2+}$ levels and $\mathrm{TH}$ on outcomes in comatose survivors of cardiac arrest.

\section{Disclosure Statement}

No competing financial interests exist.

\section{References}

Altura BM. Importance of $\mathrm{Mg}^{2+}$ in physiology and medicine and the need for ion selective electrodes. Scand J Lab Invest 1994;217:S5-S9.

Badjatia, N, Strongilis E, Gordon E, et al. Metabolic impact of shivering during therapeutic temperature modulation: The bedside shivering assessment scale. Stroke 2008;29:3242-3247.

Fawcett JW, Haxby EJ, Male DA. Magnesium: physiology and pharmacology. Br J Anaesth 1999;83:302-330.

Hollenberg J, Svennsson L, Rosengqvist M. Out-of-hospital cardiac arrest: 10 years of progress in research and treatment. J Intern Med 2013;273:572-583.

Hypothermia after Cardiac Arrest Study Group. Mild therapeutic hypothermia to improve the neurologic outcomes after cardiac arrest. N Eng J Med 2002;346:549-563.
Iseri LT. Role of magnesium in cardiac tachyarrhythmias. Am J Cardiol 1990;65:47K-50K.

Kuner T, Schoepfer R. Multiple structural elements determine subunit specificity of $\mathrm{Mg}^{2+}$ block in NMDA receptor channels. J Neurosci 1996;16:3549-3558.

Longstreth WT, Fahrenbruch CE, Olsufka M, et al. Randomized clinical trial of magnesium, diazepam, or both after out-of-hospital cardiac arrest. Neurology 2002;59;506-514.

Nielsen N, Hovdenes J, Nilsson $\mathrm{F}$, et al. Outcome, timing and adverse events in therapeutic hypothermia after out-of-hospital cardiac arrest. Acta Anaesthesiol Scand 2009;53:926-934.

Nielsen N, Sunde K, Hovdenes J, et al. Adverse events and their relation to mortality in out-of-hospital cardiac arrest patients treated with therapeutic hypothermia. Crit Care Med 2011; 39:57-64.

Polderman KH. Application of therapeutic hypothermia in the intensive care unit. Opportunities and pitfalls of a promising treatment modality-Part 2: practical aspects and side effects. Intensive Care Med 2004;30:757-769.

Polderman KH. Mechanisms of action, physiological effects, and complications of hypothermia. Crit Care Med 2009; 27[Suppl.]:S186-S202.

Polderman KH, Peerdeman SM, Girbes ARJ. Hypophosphatemia and hypomagnesemia induced by cooling in patients with severe head injury. J Neurosurg 2001;94:697-705.

Reis AG, Ferreira de Pavia E, Schvarstman C, et al. Magnesium in cardiopulmonary resuscitation: critical review. Resuscitation 2008;77:21-25.

Rubeiz GJ, Thill-Baharozian M, Hardie D, et al. Association of hypomagnesemia and mortality in acutely ill medical patients. Crit Care Med 1993;21:203-209.

Salem M, Kasinski N, Munoz R, et al. Progressive magnesium deficiency increases mortality from endotoxin challenge: protective effects of acute magnesium replacement therapy. Crit Care Med 1995;1:108-118.

Soliman HM, Mercan D, Lobo SS, et al. Development of ionized hypomagnesemia is associated with higher mortality rates. Crit Care Med 2003;31:1082-1087.

Thel MC, Armstrong MA, McNulty SE, et al. for the Duke Internal Medicine Housestaff. Randomized trial of magnesium in in-hospital cardiac arrest. Lancet 1997;350:1272-1276.

Tømte Ø, Drægni T, Mangschau A, Jacobsen D, Auestad B, Sunde K. A comparison of intravascular and surface cooling techniques in comatose cardiac arrest survivors. Crit Care Med 2011;39:443-449.

Weglicki WB, Phillips AM, Freedman, et al. Magnesium deficiency increases circulating levels of inflammatory cytokines and endothelin. Mol Cell Biochem 1992;110:169-173.

Weisinger J, Bellorin-Font E. Magnesium and phosphorus. Lancet 1998;352:391-396.

Young JB. Clinical practice: neurologic prognosis after cardiac arrest. N Eng J Med 2009;361:605-611.

Address correspondence to: Maryann Mazer-Amirshahi, PharmD, MD, MPH Department of Emergency Medicine MedStar Washington Hospital Center 110 Michigan Avenue NW Washington, DC 20010

E-mail: maryannmazer@gmail.com 
This article has been cited by:

1. Perucki William H., Hiendlmayr Brett, O'Sullivan David M., Gunaseelan Angeline C, Fayas Farruk, Fernandez Antonio B.. Magnesium Levels and Neurologic Outcomes in Patients Undergoing Therapeutic Hypothermia After Cardiac Arrest. Therapeutic Hypothermia and Temperature Management, ahead of print. [Abstract] [Full Text HTML] [Full Text PDF] [Full Text PDF with Links] [Supplemental Material]

2. Fabio Silvio Taccone, Ilaria Alice Crippa, Antonio Maria Dell'Anna, Sabino Scolletta. 2015. Neuroprotective strategies and neuroprognostication after cardiac arrest. Best Practice \& Research Clinical Anaesthesiology 29:4, 451-464. [CrossRef] 